\title{
Evaluation of an Experimental Vaccine for Atrophic Rhinitis in Piglets
}

\author{
Shijiang $\mathrm{Gu}^{1 \#}$, Yangyang Fan ${ }^{1 \#}$, Dongbo $\mathrm{Hu}^{1}$, Xiangdong $\mathrm{Li}^{1}$, Wuping Peng ${ }^{2}$, Yonghong Liao ${ }^{{ }^{*}}$ and $\mathrm{Kegong} \mathrm{Tian}^{1,3^{*}}$ \\ ${ }^{1}$ National Research Center for Veterinary Medicine, High-Tech District, Luoyang, PR China \\ ${ }^{2}$ Pulike Biological Engineering Co. Ltd, New District, Luoyang, PR China \\ ${ }^{3}$ College of Animal Science and Veterinary Medicine, Henan Agricultural University, Zhengzhou, PR China \\ * Corresponding authors: Kegong Tian, National Research Center for Veterinary Medicine, High-Tech District, Luoyang, PR China, E-mail: tiankg@263.net
}

Yonghong Liao, National Research Center for Veterinary Medicine, High-Tech District, Luoyang, PR China, E-mail: ebrain04@163.com

\#Authors equally contributed to this paper

Received date: January 23, 2017; Accepted date: February 09, 2017; Published date: February 15, 2017

Copyright: $\odot 2016 \mathrm{Gu} \mathrm{S}$, et al. This is an open-access article distributed under the terms of the Creative Commons Attribution License, which permits unrestricted use, distribution, and reproduction in any medium, provided the original author and source are credited.

\begin{abstract}
Background: Commercial swine atrophic rhinitis (AR) vaccine contains killed Bordetella bronchiseptica and $P$. multocida toxin (PMT) from Toxigenic Pasteurella multocida. The recombinant PMT proteins used as vaccine candidates were seldom reported.

Methods: In this study, we developed recombinant fragments of PMT to replace $P$. multocida toxin in AR vaccine to compare the efficacy of this vaccine candidate with the commercial vaccine.

Results: The experimental AR vaccine showed similar efficacy after bacterial challenges since there were no significant differences in clinical symptoms, turbinate lesions, lung lesions and daily body gain between the two vaccinated groups.

Discussion and conclusion: The replacement of recombinant fragments of PMT to $P$. multocida toxin in AR vaccine provided same protection as commercial vaccine after bacterial challenges. However, high yield and simple processing of recombinant fragments of PMT from E.coli cells to replace purified $P$. multocida toxin in AR vaccine will dramatically reduce the cost of vaccines and simplify the antigen preparation.
\end{abstract}

\section{Introduction}

Swine atrophic rhinitis (AR) is a multiple chronic respiratory diseasemainly caused by porcine Bordetella bronchiseptica $(\mathrm{Bb})$ and Toxigenic Pasteurella multocida $(\mathrm{T}+\mathrm{Pm})$. Clinical symptoms of this disease mainly are rhinitis, nasal deformation, nasal bone atrophy, and growth performance decline [1]. Vaccination is an effective means of prevention and control of AR. Most of AR vaccines contain antigens from $\mathrm{Bb}$ and $\mathrm{Pm}$ [2]. P. multocida toxin (PMT), a dermonecrotic toxin, is produced mainly by serogroup D strains. PMT has been considered as a good candidate for vaccine development [3]. Authentic PMT or recombinant PMT or analogues thereof have good immunological effects [3-8]. It has been reported that high levels of antibodies can be produced by inoculating sows with a mixture of three recombinant PMT fragments with/without Pasteurella multocida and the antibodies could be transmitted to their offspring with good protection against PMT challenge [9]. However, there was no report on the evaluation of experimental AR vaccine in which contains inactivated $\mathrm{Bb}$ and PMT recombinant fragments. The objective of this study was to evaluate the efficacy of a novel experimental vaccine containing inactivated $\mathrm{Bb}$ and recombinant $\mathrm{N}$-terminal and $\mathrm{C}$-terminal fragments of PMT protein.

\section{Methods}

The N-terminal (95aa-468aa) and C-terminal (837aa-1279aa) fragments of the recombinant PMT protein were expressed in E.coli cells. 100 ug recombinant proteins were used to replace 5 ug of $P$. multocida toxin in commercial AR vaccine (Pulike Bioengineering Co. Ltd, China). The above commercial vaccine was also used to immunize pigs as the manufacture's instruction in the same animal trial.

Fifteen 7-day-old piglets were divided into three groups with 5 pigs in each group. Piglets in group A were vaccinated with commercial AR vaccine via intranasal routine. Piglets in group B were vaccinated with the experimental vaccine. Piglets in group $\mathrm{C}$ worked as placebo controls. Piglets in group $\mathrm{A}$ and $\mathrm{B}$ received prime vaccination with commercial vaccine and experimental vaccine on 0 day-post vaccination, respectively. After 2 weeks, a boost vaccination was separately performed in different groups with corresponding vaccines. Three weeks later, all pigs were challenged with Bordetella bronchiseptica strain $\mathrm{HN} 8\left(4 \times 10^{9} \mathrm{CFU}\right)$ and type D toxigenic Pasteurella multocida strain $\mathrm{HB} 4\left(4 \times 10^{10} \mathrm{CFU}\right)$.

Pigs were observed for signs of AR such as sneezing, cough, wheezing and eye patches. Thirty-five days later, all experimental pigs were euthanized and examined in a blind manner for turbinate bone atrophy (TA), nasal septum deviation (NSD) and lung lesions. Turbinate bone atrophy and nasal septum deviation were assessed according to Magyar [2]. The area of lung lesions (\%) was assessed according to Hannan et al. [10]. Pigs were weighed before vaccination, at the time of bacterial challenges and 35 days after challenge. The average daily gain was calculated. Blood samples at designated days were collected to determine $\mathrm{Bb}$ and PMT antibodies. Bb agglutination antibodies were described in Pedersen [11]. PMT antibody of pig sera was also tested by using OXOID PMT antibody assay kit. The animal 
Page 2 of 4

trials were approved by the Animal Care and Ethics Committee of China National Research Center for Veterinary Medicine. Statistical differences were determined by One-way ANOVA (Prism 5.0, GraphPad Software, SanDiego, CA). Differences were considered statistically significant when $\mathrm{P}<0.05$.

\section{Results}

After vaccination, all pigs behaved normal which proved the safety of commercial vaccine and experimental vaccine in this study. After bacterial challenge, sneezing, coughing and asthma of some pigs in different groups were observed and summarized in Table 1. The clinical symptom scores of vaccinated pigs were significantly lower from that of unvaccinated control group $(\mathrm{P}<0.05)$.

\begin{tabular}{|c|c|c|c|c|}
\hline \multirow[t]{2}{*}{ Group } & \multirow{2}{*}{$\begin{array}{l}\text { Piglet } \\
\text { number }\end{array}$} & \multirow[t]{2}{*}{ Symptom $^{\mathrm{a}}$} & \multicolumn{2}{|l|}{ Lesion } \\
\hline & & & Turbinate & Lung (\%) \\
\hline \multirow{6}{*}{$\begin{array}{l}\text { Commercial } \\
\text { Vaccine }\end{array}$} & 21 & 0 & 1 & 0 \\
\hline & 22 & 0 & 6 & 0 \\
\hline & 23 & 1 & 3 & 1.4 \\
\hline & 24 & 1 & 6 & 1.4 \\
\hline & 25 & 0 & 2 & 0 \\
\hline & Mean & $0.5 \pm 0.55^{*}$ & $3.6 \pm 2.31^{*}$ & $\begin{array}{l}0.56 \quad \pm \\
0.77^{*}\end{array}$ \\
\hline \multirow{6}{*}{$\begin{array}{l}\text { Experimental } \\
\text { vaccine }\end{array}$} & 26 & 0 & 7 & 0 \\
\hline & 28 & 0 & 4 & 0 \\
\hline & 29 & 0 & 4 & 0 \\
\hline & 30 & 0 & 2 & 0 \\
\hline & 31 & 1 & 2 & 4.1 \\
\hline & Mean & $0.2 \pm 0.45^{*}$ & $3.8 \pm 2.05^{*}$ & $\begin{array}{l}0.82 \\
1.84^{*}\end{array}$ \\
\hline \multirow{6}{*}{$\begin{array}{l}\text { Unvaccinated } \\
\text { Control }\end{array}$} & 37 & 3 & 16 & 9.5 \\
\hline & 39 & 3 & 16 & 25.7 \\
\hline & 41 & 1 & 10 & 4.1 \\
\hline & 42 & 2 & 10 & 1.4 \\
\hline & 43 & 3 & 16 & 29.7 \\
\hline & Mean & $2.4 \pm 0.90^{* *}$ & $13.6 \pm 3.29^{* *}$ & $\begin{array}{l}14.08 \\
12.85^{* *}\end{array}$ \\
\hline \multicolumn{5}{|c|}{$\begin{array}{l}\text { 1-Indicates occasional sneezing, and/or occasional coughing, and/or occasional } \\
\text { asthma. }\end{array}$} \\
\hline \multicolumn{5}{|c|}{ 2-Indicates intermediate frequency of sneezing, coughing and wheezing. } \\
\hline \multicolumn{5}{|c|}{ 3-Indicates high frequency of sneezing, coughing, wheezing and/or tear spots. } \\
\hline \multicolumn{5}{|c|}{$\begin{array}{l}\text { The number of asterisks showed significant difference compared with the same } \\
\text { column }(P<0.05) \text {. }\end{array}$} \\
\hline
\end{tabular}

Table 1: Clinical signs of AR and Post-mortal findings.
In unvaccinated control group, all five pigs had a turbinate score of more than 10. There was no significant difference in clinical symptoms between commercial and experimental vaccines (Table 1). As for the lung lesion score, there was also no significant difference between two vaccinated groups. However, the scores of both two vaccinated group were significantly lower from that of unvaccinated control group ( $\mathrm{P}$ $<0.05)$.

The body weight of each individual pig was measured before vaccination, at bacterial challenge, and 35 days post-challenge, respectively. As shown by Table 2, there was no significant difference as for average daily gain among three groups before bacterial challenges. However, the average daily gain of unvaccinated pigs was significantly lower than vaccinated groups 5 weeks after challenge. There was no significant difference between two vaccinated groups.

\begin{tabular}{|c|c|c|c|c|c|c|}
\hline \multirow[t]{2}{*}{ Group } & \multirow[t]{2}{*}{$\begin{array}{l}\text { Piglet } \\
\text { number }\end{array}$} & \multicolumn{3}{|c|}{ Pig body weight (kg) } & \multicolumn{2}{|c|}{$\begin{array}{l}\text { Average daily gain } \\
\text { (g) }\end{array}$} \\
\hline & & BV & BC & PCw5 & $\begin{array}{l}\text { BV to } \\
B C\end{array}$ & $\begin{array}{l}\text { BV to } \\
\text { PCw5 }\end{array}$ \\
\hline \multirow{5}{*}{$\begin{array}{l}\text { Commercial } \\
\text { vaccine }\end{array}$} & 21 & 2.5 & 10.8 & 26.8 & \multirow[t]{5}{*}{$232.6^{*}$} & \multirow[t]{5}{*}{$392.5^{*}$} \\
\hline & 22 & 2.7 & 10 & 25.5 & & \\
\hline & 23 & 2.2 & 9.2 & 23.2 & & \\
\hline & 24 & 2.3 & 10.7 & 26.3 & & \\
\hline & 25 & 2.5 & 12.2 & 29.6 & & \\
\hline \multirow{5}{*}{$\begin{array}{l}\text { Experimental } \\
\text { vaccine }\end{array}$} & 26 & 2.3 & 11.8 & 27.8 & \multirow[t]{5}{*}{$237.7^{\star}$} & \multirow[t]{5}{*}{$395.0^{*}$} \\
\hline & 28 & 2.3 & 9.4 & 25.6 & & \\
\hline & 29 & 2.4 & 10.8 & 26.1 & & \\
\hline & 30 & 2.6 & 12 & 28.6 & & \\
\hline & 31 & 2.5 & 9.7 & 24.6 & & \\
\hline \multirow{5}{*}{$\begin{array}{l}\text { Unvaccinated } \\
\text { Control }\end{array}$} & 37 & 2.6 & 11.9 & 25.3 & \multirow[t]{5}{*}{$244^{*}$} & \multirow[t]{5}{*}{$313.5^{\star \star}$} \\
\hline & 39 & 2.4 & 10 & 21.4 & & \\
\hline & 41 & 2.5 & 11.7 & 22.5 & & \\
\hline & 42 & 2.2 & 9.2 & 25.5 & & \\
\hline & 43 & 2.4 & 12 & 22.8 & & \\
\hline \multicolumn{7}{|c|}{$\begin{array}{l}\text { The number of asterisks showed significant differenceP< }<0.05 \mathrm{BV} \text { : before } \\
\text { vaccination; } \mathrm{BC} \text { : before challenge; PCw } 5: 5 \text { weeks post-challenge }\end{array}$} \\
\hline
\end{tabular}

Table 2: Pig bodyweight gain before/after vaccination and challenge.

Antibodies to $\mathrm{Bb}$ and PMT of pigs were also measured to evaluate the efficacy of vaccination. As shown Table 3, the agglutination antibody titer to $\mathrm{Bb}$ of all pigs was less than 10 and no PMT antibodies were detected. After 3 weeks of vaccination, $\mathrm{Bb}$ antibodies of immunized pigs in groups A and group B increased to 896 and 1280, respectively. As expected, the $\mathrm{Bb}$ antibodies of unvaccinated pigs remained below 10. PMT antibodies of all pigs were tested to be negative before vaccination. As shown by Table 3, all pigs in two vaccinated groups had $100 \%$ positive antibodies to PMT. By contrast, PMT antibodies of unvaccinated remained negative throughout the study. As shown by Table 3, all pigs in two vaccinated groups had $100 \%$ (Figure 1). 


\begin{tabular}{|l|l|l|l|l|}
\hline \multirow{2}{*}{ Group } & \multicolumn{2}{|l|}{$\begin{array}{l}\text { Bb agglutination } \\
\text { titersMean reciprocal }\end{array}$} & \multicolumn{2}{l|}{ PMT antibodies\% } \\
\cline { 2 - 5 } & BV & BC & BV & BC \\
\hline Commercial vaccine & 10 & $896 \pm 350.5$ & 0 & 100 \\
\hline Experimental vaccine & 10 & $1280 \pm 783.8$ & 0 & 100 \\
\hline Unvaccinated Control & 10 & 10 & 0 & 0 \\
\hline
\end{tabular}

$\mathrm{BV}$ : before vaccination; $\mathrm{BC}$ : before challenge.

Table 3: $\mathrm{Bb}$ agglutination titers and percentage of PMT-specific positive antibodies.

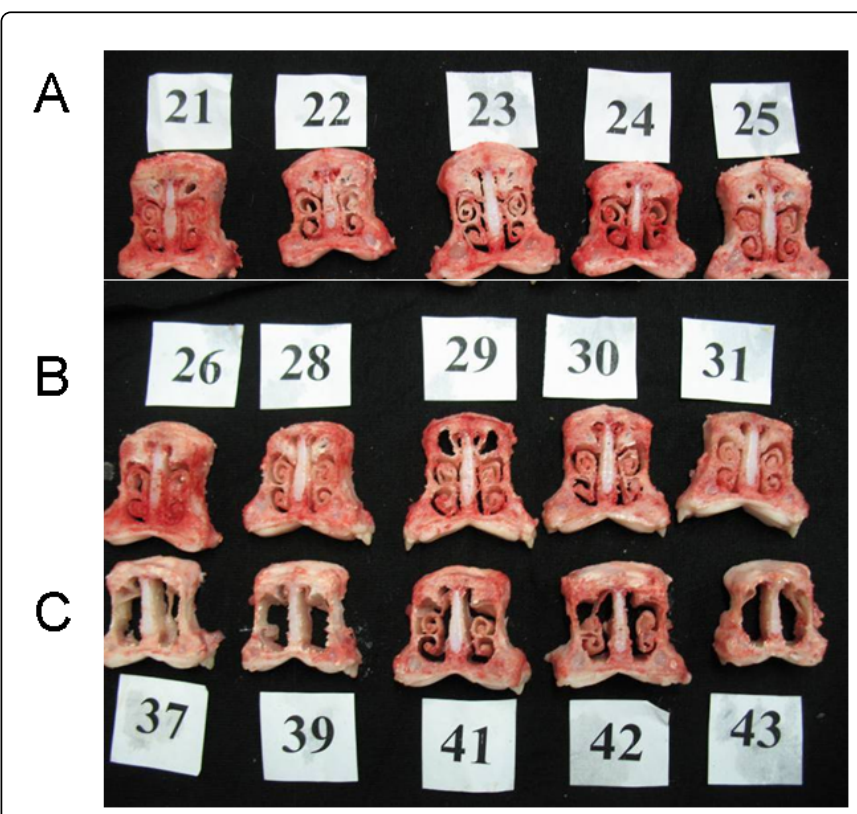

Figure 1: Porcine nasal bone picture of each individual pig in different group at necropsy. A: Commercial vaccine; B: Experimental vaccine; C: Unvaccinated Control.

\section{Discussion}

Recent studies have shown that vaccines contained PMT protein or PMT protein fragments are effective against AR [5-9,12]. In this study, an experimental AR vaccine was developed by replacing the extracted PMT components in commercial vaccines with recombinant $\mathrm{N}$ terminal and C-terminal fragment of PMT expressed in E.coli. The results showed that vaccinated pigs had the same average daily gain of piglets after immunization with these two vaccines. By contrast, the average daily gain of pigs in two vaccinated groups was significantly higher than that of pigs in control group. Scores of clinical symptoms, turbinate lesions and lung lesions of two vaccinated groups were significantly lower than those of unvaccinated challenge group but had no significant difference between two vaccinated groups. All above results showed that this experimental AR vaccine containing recombinant PMT protein fragments had same efficacy for ensuing bacterial challenge as commercial vaccine containing PMT toxoid.

Immunization of sows with $\mathrm{Bb}$ and PMT toxoid had provided a good level of antibodies, which were transmitted to their offspring [4].
In this study, immunization of these two vaccines also produced a high level of antibodies in piglets. Three weeks after vaccination, the mean antibodies of $\mathrm{Bb}$ in two vaccinated groups increased rapidly to 896 and 1280 , respectively. PMT antibodies of all pigs in two vaccinated groups also turned to be positive. The above similar results of antibody seroconversion rates after immunizations showed that recombinant PMT protein fragments had the same immunological effects as natural PMT toxoid.

\section{Conclusion}

The immunization of piglets with inactivated $\mathrm{Bb}$ and $\mathrm{N}$-terminal and C-terminal fragments of recombinant PMT protein resulted in a good protection against a combined challenge of $\mathrm{Bb}$ and $\mathrm{Pm}$.

\section{Conflict of interest}

The authors declare that they have no conflict of interest.

\section{Acknowledgments}

This study was funded by grant from Luoyang Heluo Talent Plan (Dr. Kegong Tian).

\section{References}

1. Horiguchi Y (2012) Swine atrophic rhinitis caused by pasteurella multocida toxin and bordetella dermonecrotic toxin. Curr Top Microbiol Immunol. 361: 113-129.

2. Magyar T, King VL, Kovács F (2002) Evaluation of vaccines for atrophic rhinitis--a comparison of three challenge models. Vaccine. 20: 1797-1802.

3. Foged NT (1992) Pasteurella multocida toxin. The characterisation of the toxin and its significance in the diagnosis and prevention of progressive atrophic rhinitis in pigs. APMIS Suppl. 25: 1-56.

4. Kobisch M, Pennings A (1989) An evaluation in pigs of Nobi-Vac AR and an experimental atrophic rhinitis vaccine containing P multocida DNTtoxoid and B bronchiseptica. Vet Rec. 124: 57-61.

5. Foged NT, Nielsen JP, Jorsal SE (1989) Protection against progressive atrophic rhinitis by vaccination with Pasteurella multocida toxin purified by monoclonal antibodies. Vet Rec. 125: 7-11.

6. Petersen SK, Foged NT, Bording A, Nielsen JP, Riemann HK, et al. (1991) Recombinant derivatives of Pasteurella multocida toxin: candidates for a vaccine against progressive atrophic rhinitis. Infect Immun. 59: 1387-1393.

7. Nielsen JP, Foged NT, Sørensen V, Barfod K, Bording A, et al. (1991) Vaccination against progressive atrophic rhinitis with a recombinant Pasteurella multocida toxin derivative. Can J Vet Res. 55: 128-138.

8. To H, Someno S, Nagai S (2005) Development of a genetically modified nontoxigenic Pasteurella multocida toxin as a candidate for use in vaccines against progressive atrophic rhinitis in pigs. Am J Vet Res. 66: 113-118.

9. Liao CM, Huang C, Hsuan SL, Chen ZW, Lee WC, et al. (2006) Immunogenicity and efficacy of three recombinant subunit Pasteurella multocida toxin vaccines against progressive atrophic rhinitis in pigs. Vaccine. 24: 27-35.

10. Hannan PC, Bhogal BS, Fish JP (1982) Tylosin tartrate and tiamutilin effects on experimental piglet pneumonia induced with pneumonic pig lung homogenate containing mycoplasmas, bacteria and viruses. Res Vet Sci. 33: 76-88.

11. Pedersen KB (1975) The serology of Bordetella bronchiseptica isolated from pigs compared with strains from other animal species. Acta Path Microbiol Scand Sect B. 83: 590-594.

12. Lee J, Kang HE, Woo HJ (2012) Protective immunity conferred by the Cterminal fragment of recombinant Pasteurella multocida toxin. Clin Vaccine Immunol. 19: 1526-1531. 